\title{
Characteristics of Writing in Parkinson's Disease: Focused on Pen Pressure, Letter Size, and Writing Speed
}

\author{
Han Sol Lee ${ }^{a}$, Jinyoung Youn ${ }^{\mathrm{b}, c}$, Jin Whan Cho ${ }^{\mathrm{b}, c}$, Jong Hyeon $\mathrm{Ahn}^{\mathrm{b}, c}$, Ji Hye Yoon ${ }^{\mathrm{d}}$, Duk L. Na ${ }^{\mathrm{b}, c}$ \\ ${ }^{a}$ Department of Speech Pathology, Graduate School of Health Sciences, Hallym University, Chuncheon, Korea \\ ${ }^{b}$ Department of Neurology, Samsung Medical Center, Sungkyunkwan University School of Medicine, Seoul, Korea \\ ${ }^{c}$ Neuroscience Center, Samsung Medical Center, Seoul, Korea \\ ${ }^{d}$ Division of Speech Pathology and Audiology, College of Natural Sciences, Hallym University, Chuncheon, Korea
}

\author{
Correspondence: Ji Hye Yoon, $\mathrm{PhD}$ \\ Division of Speech Pathology and Audiology, \\ College of Natural Sciences, Hallym University, \\ 1 Hallymdaehak-gil, Chuncheon 24252, Korea \\ Tel: $+82-33-248-2224$ \\ Fax: +82-33-256-3420 \\ E-mail: j.yoon@hallym.ac.kr
}

Received: January 5, 2020

Revised: January 28, 2020

Accepted: February 7, 2020

This material is based upon work supported by the Ministry of Trade, Industry \& Energy (MOTIE, Korea) under Industrial Technology Innovation Program (10063384)

This research was supported by Hallym University Research Fund in 2019 (No. HRF-201912-007).

\begin{abstract}
Objectives: Movement disorders in Parkinson's disease (PD) can affect not only letter size but also pen pressure and writing speed. The purpose of this study was to investigate the characteristics of writing with focus on pressure, size, and speed in PD. Methods: Sixtythree subjects (38 in a PD group and 25 in a normal adult [NA] group) performed tasks involving drawing along dotted lines and sentence writing using a tablet $\mathrm{PC}$, digital pen, and software that could measure pen pressure, stroke length, and duration. Results: In the task involving drawing along a dotted line, the PD group showed significantly slower writing speed compared with the findings in the NA group. Additionally, in the task involving sentence writing, the PD group showed significantly weaker pen pressure, smaller letter size, and slower writing speed compared with the NA group. Moreover, both groups showed a positive correlation between letter size and writing speed, but only the PD group showed a positive correlation between pen pressure and writing speed. Conclusion: Difficulty in motor control of strength, size, speed, etc. owing to PD is reflected in pen pressure, letter size, and writing speed when performing a writing task. Our results show an importance in measuring multiple factors such as pen pressure and writing speed in the characteristics of writing in PD, which has until now, has been focused only on letter size.
\end{abstract}

Keywords: Parkinson's disease, Writing, Pen pressure, Writing speed
파킨슨병(Parkinson's disease, PD)은 중뇌 흑질 치밀부(substantia nigra pars compacta)의 손상으로 인해 도파민(dopamine)의 소 실이 나타나는 대표적인 신경퇴행성질환으로(Ahn \& Chung, 2009; Corti et al., 2005; Gelb, Oliver, \& Gillman, 1999; Jankovic, 2008) 치매, 뇌졸중과 함께 3 대 노인성 뇌 질환 중 하나로 손꼽히며, 신경 퇴행성질환 중 알츠하이머병(Alzheimer's disease) 다음으로 발병 률이 높다(Seol, 2008; Health Insurance Review \& Assessment Service, 2018). PD에서는 신경전달물질의 불균형으로 대뇌피질과 피질하 영역을 잇는 기저핵 조절 회로(basal ganglia circuit)의 신경 학적 결함이 나타나는데(Freed, 2012), 이는 주로 운동을 계획하고 실행하는 운동 장애로 반영되며(Freed, 2012), 휴식 시 떨림(resting tremor), 서동증(bradykinesia), 강직(rigidity), 자세불안정(postural instability) 등을 보인다. 이러한 운동학적 증상은 50-60\% 이상 의 도파민이 소실되었을 때부터 나타나면서(Fearnley \& Lees, 1991; Morrish, Rakshi, Bailey, Sawle, \& Brooks, 1998) 다양한 운동학적 활동에 영향을 미친다.

쓰기(writing)는 언어 능력뿐만 아니라 주의력, 시공간 능력, 작 업 기억 등의 다양한 인지기능의 상호작용으로 이루어지며(Kim, 2012), 운동 계획 및 프로그래밍, 운동 집행 등의 운동 능력이 밀접 하게 관여하는 복합적인 활동이다. 특히 손이라는 매개체를 통하 여 수행이 이루어지기 때문에 필기도구를 잡고, 적당한 힘을 가하 고, 속도를 적절하게 조절하며, 글자 크기를 일정하게 조절하여 쓰 
는 등의 운동 능력이 필히 수반되어야 한다. 실서증(agraphia)은 다 양한 원인 질환에 의해 후천적으로 발생하는 모든 쓰기 장애를 통 칭하며(Yoon, $\mathrm{Na}, \& \mathrm{Kim}, 2009)$, 크게 중추실서증(central agraphia)과 말초실서증(peripheral agraphia)으로 나뉜다. 언어의 표상을 구성하는 철자체계 단계의 결함에 기인한 중추실서증과 달리 말초 실서증은 철자 단계에서 형성된 표상을 적절한 프로그래밍을 통하 여 손의 움직임을 조절하면서 실제적으로 글자의 형태를 산출하는 쓰기 집행 단계의 결함에 기인한 쓰기 장애를 말한다(Kim, 2012; Yoon et al., 2009). 운동 범위의 감소, 운동 강도의 저하와 같이 대체 적으로 운동 능력이 저하되는 특징이 두드러지는 $\mathrm{PD}$ 에서는 말초 실서증의 다양한 유형 중 하나로 글자의 크기가 비정상적으로 작아 지는 소자증(micrographia)이 나타난다(Becker et al., 2002; McLennan, Nakano, Tyler, \& Schwab, 1972). 소자증은 PD의 초기 증상 중 하나일 수 있으며(Becker et al., 2002; McLennan et al., 1972), $\mathrm{PD}$ 환자의 50-60\%에서 관찰되는 것으로 알려져 있다(Shukla et al., 2012).

최근 들어 알파벳을 사용하는 국외 PD 환자 대상 연구에서 $\mathrm{PD}$ 의 다양한 운동 증상과 소자증의 관계가 설명되고 있으며, 소수이 기는 하나 글자 크기뿐만 아니라 태블릿 PC와 디지털 펜을 사용하 여 필압(pen pressure)과 쓰기 속도(writing speed)를 측정한 연구 가 진행되고 있다(Smits et al., 2014; Taleb, Khachab, Mokbel, \& Likforman-Sulem, 2017, 2018; Zham, Kumar, Dabnichki, Poosapadi Arjunan, \& Raghay, 2017; Zham et al., 2019). 기존 연구들을 살펴보면, 아르키메데스 나선 또는 단순한 획을 반복하여 그리는 과제(예: 삼각파) 또는 문장 쓰기 과제를 실시하였으며 필압은 측정 기기의 사양(예: 1,024 단계) 내에서 자동 측정하고, 쓰기 속도는 자 소를 쓰는 데 걸린 소요시간(duration)를 자동 측정하거나 자소의 길이를 자동 측정하여 자소를 쓰는 소요시간으로 나누어 계산한 속도(speed)로 산정하였다. 이 중, 점선으로 구성된 아르키메데스 나선 따라 그리기 과제를 실시하여 $\mathrm{PD}$ 환자와 정상인의 필압 및 쓰 기 속도를 측정하고 비교한 연구(Zham et al., 2017)에서는 PD 환자 의 필압이 정상인에 비하여 저하되고 쓰기 속도가 느린 것으로 나 타났다. 이름과 성 쓰기, 필기체 ' $\ell$ '을 반복하여 쓰기, 단어 반복하 여 쓰기, 삼각파, 사각파 10 번 그리기의 여러 가지 과제를 실시하여 $\mathrm{PD}$ 환자와 정상인의 필압 및 쓰기 속도를 측정하고 비교한 연구 (Taleb et al., 2017, 2018) 또한 PD 환자의 필압이 정상인에 비하여 저하되고, 문장 쓰기와 필기체 ' $\mathrm{e} \ell$ '을 반복하여 쓰기에서 $\mathrm{PD}$ 환자 의 평균 쓰기 속도가 느린 것으로 나타났으며, 문장 쓰기 과제에서 가장 두드러지게 나타났다. 이러한 연구 결과들을 토대로 Letanneux, Danna, Velay, Viallet와 Pinto (2014)는 'PD 실서증(PD Dys- graphia)'이라는 용어를 제안하면서 크기 외의 다른 운동학적 요인 을 함께 살펴봐야한다고 주장하였다.

한글을 사용하는 국내 $\mathrm{PD}$ 환자 대상 연구에서는 소자증 현상이 보고되었으나(Chang, Cho, Yoon, \& Kim, 2016; Kim et al., 2015; Kim, Lee, Park, Lee, \& Na, 2005) 필압과 쓰기 속도를 측정한 연구 는 전무한 실정이다. 쓰기의 수행은 각 문자 체계의 특성을 반영할 수 있으며, 영어권의 알파벳과 우리나라의 한글은 철자나 형태를 포함하는 문자체계가 매우 다르기 때문에 국외의 연구 결과를 국 내에 그대로 적용시키기에는 어려움이 있다. 특히 한글은 시공간적 인 관점에서 그 특수성이 두드러진다. 한글은 각 자소가 음절이라 는 사각의 형태 안에서 공간적인 규칙성을 가지고 조합되는 모아쓰 기 형식을 취하며, 방향에 따라 자소가 좌우 방향으로 배열되는 횡 단쓰기, 자소가 상하 방향으로 배열되는 종단 쓰기, 횡단쓰기와 종 단쓰기가 혼합되어 있는 종횡단 혼합쓰기로 분류할 수 있다(Yoon, Shin, Kim, Suh, \& Kim, 2006). 따라서 횡단쓰기 형태의 일방향으 로만 배열되는 알파벳과는 달리, 한글은 각 자소 뿐만 아니라 음절 내에서 자소의 구성이나 각 자소들 간의 조절이 필요하여 힘, 크기, 속도의 측면에서 다양한 양상이 나타날 수 있기 때문에 한글을 사 용하는 우리나라 환자를 대상으로 필압과 쓰기 속도를 측정한 연 구가 필요하다.

이와 더불어 $\mathrm{PD}$ 소자증은 글자를 써나갈수록 글자 크기가 점차 작아지는 점진적 소자증(progressive micrographia)과 일정하게 작 은 글자 크기로 글자를 쓰는 일관적 소자증(consistent micrographia)으로 나타날 수 있다. 점진적 소자증의 경우, 기존의 연구(Chang et al., 2016; Kim et al., 2015; Kim et al., 2005)에서는 처음 쓴 단어 또는 음절과 마지막으로 쓴 단어 또는 음절을 비교하여 쓰기 수행 상에서의 글자 크기의 변화를 확인하였다. 그러나 소자증에 영향 을 미치는 운동적 측면을 다각적으로 고려하여 볼 때, 크기와 더불 어 필압과 쓰기 속도가 쓰기 수행이 진행되어감에 따라 어떻게 변 화하는지를 확인한 연구는 미비한 실정이다.

이에 본 연구는 PD 환자와 정상 성인(normal adult, $\mathrm{NA}$ ) 집단을 대상으로 태블릿 PC와 디지털 펜, 그리고 필압과 쓰기 속도를 측정 할 수 있는 소프트웨어를 사용하여 다음을 확인하고자 하였다. 첫 째, 쓰기를 위한 기초적인 운동 능력을 확인하기 위하여 가로/세로 점선 따라 그리기를 시행한 후 필압과 쓰기 속도를 살펴보았다. 둘째, $\mathrm{PD}$ 의 운동학적 측면이 쓰기에 미치는 영향을 다각적으로 확인하기 위하여 앞/뒤가 동일한 음절로 이루어진 13 음절의 1 문장(여보안경 안보이네안경안보여) 쓰기 과제에서의 필압, 글자 크기 및 쓰기 속도 를 확인하고 앞 3 음절과 뒤 3 음절의 차이를 비교하여쓰기 수행상의 변화를 확인하였다. 마지막으로는 세 변인 간의 상관을 분석하였다. 


\section{연구방법}

\section{연구대상}

본 연구에는 만 50-80세 사이의 남녀 중 다음 선정 기준에 맞는 $\mathrm{PD}$ 환자 38 명, NA 25명, 총 63명이 참여하였다. PD 환자는 서울 소 재의 종합병원 신경과에 외래로 내원하여 신경과 전문의로부터 신 경학적 진찰 및 병력을 바탕으로 한 임상적 진단이 특발성 파킨슨 병(idiopathic Parkinson's disease)으로 진단된 환자를 모집하였으 며, 자세한 선정 기준은 다음과 같다. 1) 항파킨슨 약물을 복용하고 있으며, 2) 모든 검사 시 항파킨슨제를 복용한 일정한 시간과 그 다 음 복용할 시간 사이인 약 효과가 지속되는 상태(on-state)이고, 3) 신경과 전문의로부터 운동 증상을 평가하는 통합형 파킨슨병 평가 척도(Unified Parkinson's Disease Rating Scale, UPDRS)-part III 와 수정된 호엔야 척도(Modified Hoehn and Yahr (H\&Y) scale)를 실시하여 H\&Y 0-2.5 사이의 운동 증상이 경도(mild)에 해당하는 환자이며, 4) 뇌심부자극술(deep brain stimulation)을 받지 않았 고, 5) 한국판 몬트리올 인지 평가(Korean version of the Montreal Cognitive Assessment, MoCA-K; Lee et al., 2008)를 실시하여 23 점 이상으로 인지기능이 정상 범주로 판단되며, 6) 한국판 벡 우울 척도(Korean Version of Beck Depression Inventory, K-BDI; Lee \& Song, 1991)를 실시하여 9점 이하로 우울감이 없는 자를 대상으로 하였다.

$\mathrm{NA}$ 는 서울, 경기, 강원 지역의 경로당 및 노인복지관에서 모집하 였으며, 자세한 선정 기준은 다음과 같다. 1) 건강선별설문지(Christensen, Multhaup, Nordstrom, \& Voss, 1991)를 실시하여 인지기능 에 영향을 미치는 정신적, 신경학적, 신체적 질환의 병력이 없으며, 2) 한국판 몬트리올 인지 평가(MoCA-K; Lee et al., 2008)를 실시하 여 23점 이상으로 인지기능이 정상 범주로 판단되고, 3) 한국판 벡 우울 척도(K-BDI; Lee \& Song, 1991)를 실시하여 9점 이하로 우울 감이 없는 자를 대상으로 하였다.

대상자 제외 기준은 다음과 같다. $\mathrm{PD}$ 집단, $\mathrm{NA}$ 집단 모두 1) 한 국어를 모국어로 사용하지 않는 경우, 2) 왼손잡이인 경우, 3) 초등 학교 졸업 학력 미만인 경우, 4) 과거에 뇌손상 및 기타 신경학적 병 력이 있는 경우, 5) 과제 수행이 불가능할 정도의 청력과 시력을 가 지고 있는 경우는 대상자에서 제외하였다. Table 1 에 나타난 바와 같이 $\mathrm{PD}$ 집단과 $\mathrm{NA}$ 집단의 연령, 교육년수, $\mathrm{MoCA}-\mathrm{K}$ 점수, $\mathrm{K}-\mathrm{BDI}$ 점수의 차이가 유의미한지 알아보기 위해 $t$-검정을 실시한 결과, 두 집단 간의 연령 $\left(t_{(61)}=.539, p=.593\right)$, 교육년수 $\left(t_{(61)}=1.527, p=.132\right)$ $\mathrm{MoCA}-\mathrm{K}$ 점수 $\left(t_{(61)}=-1.166, p=.248\right), \mathrm{K}-\mathrm{BDI}$ 점수 $\left(t_{(61)}=1.826, p=.075\right)$ 모두 통계적으로 유의미한 차이가 없었다.
Table 1. Participants' characteristics

\begin{tabular}{lccr}
\hline Characteristic & $\mathrm{PD}(\mathrm{N}=38)$ & $\mathrm{NA}(\mathrm{N}=25)$ & $t$ \\
\hline Gender (M:F) & $19: 19$ & $10: 15$ & \\
Age & $65.053 \pm 6.621(53-80)$ & $63.800 \pm 10.296(50-78)$ & .539 \\
Education & $13.053 \pm 3.834(6-22)$ & $11.480 \pm 4.244(6-22)$ & 1.527 \\
MoCA-K & $26.184 \pm 2.323(23-30)$ & $26.840 \pm 1.951(23-30)$ & -1.166 \\
K-BDI & $4.711 \pm 2.598(0-9)$ & $3.240 \pm 3.431(0-9)$ & 1.826 \\
POT (years) & $5.105 \pm 3.351(1-15)$ & & \\
UPDRS-part III & $13.618 \pm 6.276(3-27)$ & & \\
H\&Y scale & $1.592 \pm 0.518(1-2.5)$ & & \\
\hline
\end{tabular}

Values are presented as mean $\pm S D$ (range).

$\mathrm{PD}=$ patients with Parkinson's disease; $\mathrm{NA}=$ normal adults; $\mathrm{M}=$ Male; $\mathrm{F}=$ Female. MoCA-K=Korean version of the Montreal Cognitive Assessment (Lee et al., 2008); K-BDI = Korean Version of Beck Depression Inventory (Lee \& Song, 1991); POT = Post Onset Time; UPDRS = Unified Parkinson's Disease Rating Scale; H\&Y scale=Modified Hoehn and Yahr scale.

\section{자료수집 도구}

\section{수집 도구}

본 연구의 검사 도구는 쓰기 수행 시 기기적 측정을 위하여 12 인 치 $(30.37 \mathrm{~cm})$ 의 태블릿 PC '삼성전자 갤럭시북 12.0 (Samsung Galaxy Book 12.0, SM-W720NZKAKOO)'을 사용하였고, 필압과 획의 길이, 쓰기 시간을 측정할 수 있도록 개발된 ‘BAT (Brief Agraphia Test; Na \& Yoon, In press)' 소프트웨어를 사용하였다. 펜은 실제 연필 모양으로 디자인 된 전자기 유도(Electro Magnetic Resonance) 방식의 ‘스테들러 노리스 디지털펜(Staedtler Noris Digital Pencil, GP-U999ERIPAAB)'을 사용하였다. 이 펜은 펜촉 지름 $0.7 \mathrm{~mm}$, 펜 대 두께 $9 \mathrm{~mm}$ 로 실제 연필과 유사하며, 디지털펜을 사용할 때 태 블릿 PC 화면에 손이 닿는 것을 인식하지 않는 팜 리젝션(palm rejection) 기술이 적용되어 태블릿 PC의 사용경험이 적은 장노년층 도 태블릿 PC에 쓰기 과제를 수행하는 것이 어렵지 않다.

\section{과제}

먼저 가로/세로 점선 따라 그리기 과제는 쓰기의 기초가 되는 운 동학적 능력을 살펴보기 위해 제작하였으며, 비교에 용이하도록 길 이를 통제하기 위해 태블릿 PC 화면에 각각 점선으로 구성된 $5 \mathrm{~cm}$ 의 가로 선과 세로 선을 제시하였다. 문장 쓰기 과제는 Chang 등 (2016)의 연구를 참고하여 자소와 음소가 일대일로 대응하는 13음 절의 단일 문장 자극 '여보안경안보이네안경안보여'로 변형하여 사 용하였다. 이 자극에는 한글의 시공간적 특성인 종단(예: 보), 횡단 (예: 여), 종횡단 혼합(예: 안) 방향의 자소 배열이 골고루 포함되어 있으며, 쓰기 수행이 진행되는 양상을 확인하기 용이하도록 문장 의 앞/뒤 3음절을 동일한 음절로 구성하였다. Chang 등(2016)의 연 구를 참고했을 때 짧은 문장을 여러 번 반복하여 쓰는 경우, 문장 
의 첫 글자가 다시 커지는 현상(예: 여보게저기저게보여여보게저기저게보여 $\cdots)$ 이 나타났기 때문에 13음절의 단일 문장으로 선정하였으며, 태블릿 $\mathrm{PC}$ 화면에 받아쓰는 과제이므로 한 줄로 쓰기 적합한 길이로 선정 하였다.

\section{연구 절차}

본 연구는 조용하고 독립된 공간에서 개별적으로 진행하였다. 본 연구의 모든 절차는 종합병원 생명윤리위원회의 승인(IRB 201806-140-005)을 받았으며, 모든 대상자들에게 연구 목적 및 연구 절 차, 개인정보 보호, 보상에 대해 설명한 후, 생명윤리위원회의 승인 을 받은 동의서에 서명을 받았다. 이후 선별검사(건강선별설문지, $\mathrm{MoCA}-\mathrm{K}, \mathrm{K}-\mathrm{BDI})$ 를 실시하여 기준에 부합하는 대상자를 선별하 였다. 선정 기준에 적합하다고 판단된 대상자는 쓰기 검사를 실시 하였다. 쓰기 검사는 모든 대상자가 가로/세로 점선 따라 그리기, 문 장 쓰기 순으로 실시하였으며, “손바닥 또는 손날이 닿아도 괜찮으 니 평소 종이에 쓰시는 것처럼 편하게 펜을 쥐고 쓰세요.”라고 지시 문을 제공하였다. 가로/세로 점선 따라 그리기 과제는 태블릿 PC 화면에 점선으로 구성된 $5 \mathrm{~cm}$ 의 가로 선과 세로 선을 제시한 후 따 라 긋는 것으로 하였다. 문장 쓰기 과제는 연구자가 불러주는 13음 절의 1 문장 ‘여보안경안보이네안경안보여'를 끝까지 들은 후 태블릿 $\mathrm{PC}$ 화면에 띄어쓰기 없이 한 줄로 받아쓰도록 하였다. 모든 대상자 에게 문장은 한 번만 들려주었다.

\section{자료 분석}

필압은 펜으로 글자를 쓰면서 누르는 압력으로 태블릿 PC화면 에 펜이 닿은 시점(pen-down)부터 펜을 뗀 시점(pen-up)까지의 한 획 내에서 모든 필압 값이 본 연구에 사용된 태블릿 $\mathrm{PC}$ 에서 측정될 수 있는 범위인 0-4,096 단계 내에서 측정된 후, 이를 0-1 범위로 변 환된 값을 사용하였다. 획 마다 측정된 값은 합산되어 각 음절 별 평균으로 산정되었다. 음절을 이어서 작성한 경우에는 정확한 결과 값을 얻기 어려우므로 분석'에서 제외하였다.

글자 크기는 2004년에 미국국립보건원(NIH)에서 개발한 'Image J' 소프트웨어를 사용하여 각 음절의 상하좌우의 극단을 기준 으로 지정한 사각형의 면적을 잡아 픽셀 단위로 측정하였다. Figure 1 에 나타난 바와 같이 신뢰로운 측정을 위하여 $800 \%$ 확대하고, 배경 색깔을 초록색으로 바꾸어 글자의 픽셀이 잘 보이도록 설정 한 후측정하였다.

쓰기 속도는 글자를 쓰는 소요시간(duration)으로, 분석 시 글자 크기의 영향을 받을 수 있기 때문에 소자증을 보이는 PD 환자를 $\mathrm{NA}$ 와 비교하는 데 용이하지 않다. 따라서 본 연구에서는 글자 크

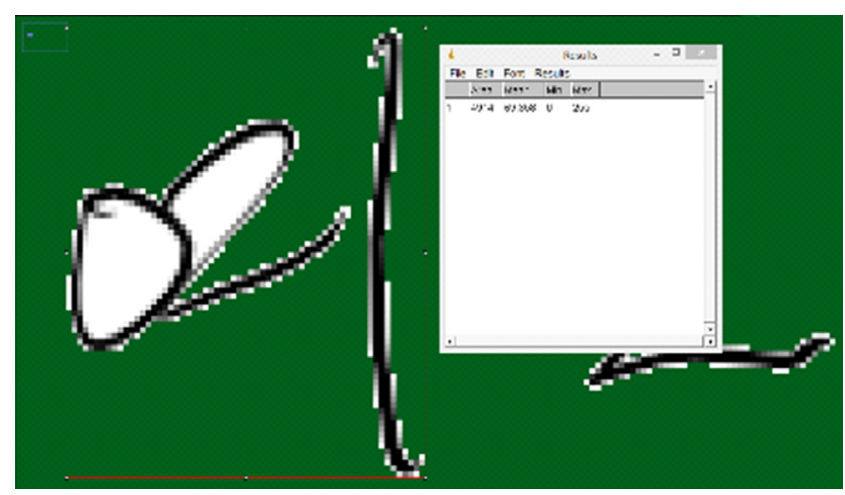

Figure 1. Example of measuring letter size used 'Image J'.

기를 통제하면서 실제 쓰기 속도를 분석하기 위해 태블릿 PC 화면 에 펜이 닿은 시점부터 펜을 뗀 시점까지 측정되는 $\mathrm{mm}$ 단위의 한 획의 길이를 $\mathrm{ms}$ 단위의 한 획을 쓰는 데 걸린 소요시간으로 나눈 $\mathrm{mm} / \mathrm{ms}$ 단위의 속력(speed)을 계산하였다.

\section{자료의 통계처리}

연구 결과는 'SPSS version 25.0 (IBM Corp., Armonk, NY, USA)' 소프트웨어를 사용하여 통계처리를 하였다. 첫 번째로, 두 집단 간 가로/세로 점선 따라 그리기 과제에서 쓰기 수행력(필압, 쓰기 속 도)이 통계적으로 유의미한 차이가 있는 지 알아보기 위해 독립표 본 $t$-검정(independent $t$-test)을 실시하였다. 두 번째로, 두 집단 간 문장 쓰기 과제에서 전체 음절, 앞 3음절, 뒤 3음절의 쓰기 수행력 (필압, 글자 크기, 쓰기 속도)이 통계적으로 유의미한 차이가 있는 지 알아보기 위해 독립표본 $t$-검정(independent $t$-test)을, 각 집단의 앞 3음절과 뒤 3음절 간의 쓰기 수행력(필압, 글자 크기, 쓰기 속도) 이 차이가 있는지 확인하기 위하여 대응표본 $t$-검정(paired $t$-test) 을 실시하였다. 마지막으로, 필압, 글자 크기, 쓰기 속도의 상관에 대 한 통계적 분석을 위해 피어슨 적률 상관계수(Pearson's product moment correlation coefficient)를 실시하였다.

\section{연구결과}

\section{가로/세로 점선 따라 그리기 수행력}

쓰기를 위한 기초적인 운동 양상을 살펴보기 위해가로/세로 점선 따라 그리기 과제를 실시하여 집단 간 필압과 쓰기 속도의 차이를 살 펴본 결과, 필압은 $\mathrm{PD}$ 집단 평균 $.67521(\mathrm{SD}=.14717), \mathrm{NA}$ 집단 평균 $.72518(\mathrm{SD}=.12789)$ 로 두 집단 간의 유의미한 차이가 없었다. 쓰기 속도는 $\mathrm{PD}$ 집단 평균 $.02665(\mathrm{SD}=.01405)$ 로 $\mathrm{NA}$ 집단 평균 .04874 $(\mathrm{SD}=.04098)$ 보다 유의미하게 느린 것으로 나타났다(Table 2). 


\section{문장 쓰기 수행력}

필압 차이

문장 쓰기 과제를 실시하여 집단 간 필압의 차이를 살펴본 결과 (Table 3), 전체 음절에서 $\mathrm{PD}$ 집단은 평균 .63581 (SD=.11381)로, $\mathrm{NA}$ 집단 평균 $.72188(\mathrm{SD}=.08718)$ 보다 유의미하게 필압이 저하된 것으로 나타났다 $\left(t_{(61)}=-3.209, p=.002\right)$. 앞 3 음절에서 $\mathrm{PD}$ 집단은 평균 .61517 $(\mathrm{SD}=.12138)$ 로, $\mathrm{NA}$ 집단 평균 $.69310(\mathrm{SD}=.09726)$ 보다 유의미하게 필압이 저하된 것으로 나타났다 $\left(t_{(61)}=-2.690, p=.009\right)$. 뒤 3음절에서 $\mathrm{PD}$ 집단은 평균 .65302 $(\mathrm{SD}=.11551)$ 로, $\mathrm{NA}$ 집단 평 균 .74020 (SD =.09234)보다 유의미하게 필압이 저하된 것으로 나 타났다 $\left(t_{(61)}=-3.164, p=.002\right)$.

각 집단의 앞 3 음절과 뒤 3 음절 필압의 차이를 살펴본 결과, $\mathrm{PD}$

Table 2. Descriptive statistics of pen pressure and writing speed in drawing along a dotted lines task

\begin{tabular}{lccc}
\hline & $\mathrm{PD}(\mathrm{N}=38)$ & $\mathrm{NA}(\mathrm{N}=25)$ & \multicolumn{1}{c}{$t$} \\
\hline Pen pressure & $.67521(.14717)$ & $.72518(.12789)$ & -1.387 \\
Writing speed $(\mathrm{mm} / \mathrm{ms})$ & $.02665(.01405)$ & $.04874(.04098)$ & $-2.597^{*}$ \\
\hline
\end{tabular}

Values are presented as mean (SD).

$\mathrm{PD}=$ patients with Parkinson's disease; NA = normal adults.

${ }^{*} p<.05$.

Table 3. Descriptive statistics of pen pressure in sentence writing task

\begin{tabular}{lccc}
\hline & $\mathrm{PD}(\mathrm{N}=38)$ & $\mathrm{NA}(\mathrm{N}=25)$ & $t$ \\
\hline Whole syllable & $.63581(.11381)$ & $.72188(.08718)$ & $-3.209^{* *}$ \\
First 3-syllable & $.61517(.12138)$ & $.69310(.09726)$ & $-2.690^{* *}$ \\
Final 3-syllable & $.65302(.11551)$ & $.74020(.09234)$ & $-3.164^{* *}$ \\
\hline
\end{tabular}

Values are presented as mean (SD).

$\mathrm{PD}=$ patients with Parkinson's disease; NA = normal adults.

${ }^{* *} p<.01$.
집단은 $t_{(37)}=-4.935, p=.000, \mathrm{NA}$ 집단은 $t_{(24)}=-4.103, p=.000$ 으로 두 집단 모두 앞 3 음절보다 뒤 3 음절이 유의미하게 필압이 강한 것 으로 나타났다.

\section{글자 크기 차이}

문장쓰기 과제를 실시하여 집단 간 글자 크기의차이를 살펴본 결 과(Table 4), 전체 음절에서 $\mathrm{PD}$ 집단 평균 3107.19231 (SD = 1524.14749) 로, NA 집단 평균 $4085.42462(\mathrm{SD}=1930.40684)$ 보다 유의미하게 글자 크기가 작은 것으로 나타났다 $\left(t_{(61)}=-2.240, p=.029\right)$. 앞 3 음절 에서 $\mathrm{PD}$ 집단은 평균 $3585.28070(\mathrm{SD}=1751.36122)$ 로, $\mathrm{NA}$ 집단 평 균 4619.92000 (SD = 1943.89652)보다 유의미하게 글자 크기가 작은 것으로 나타났다 $\left(t_{(61)}=-2.196, p=.032\right)$. 뒤 3 음절에서 $\mathrm{PD}$ 집단은 평균 3125.53509 ( $\mathrm{SD}=1658.90861)$ 로, $\mathrm{NA}$ 집단 평균 4207.24000 $(\mathrm{SD}=2450.05583)$ 보다 유의미하게 글자 크기가 작은 것으로 나타 났다 $\left(t_{(61)}=-2.092, p=.041\right)$.

각 집단의 앞 3 음절과 뒤 3 음절 글자 크기의 차이를 살펴본 결과, $\mathrm{PD}$ 집단은 $t_{(37)}=3.405, p=.002$ 로 앞 3 음절보다 뒤 3 음절의 글자 크 기가 유의미하게 작은 것으로 나타났으나, NA 집단은 $t_{(24)}=1.485$, $p=.151$ 로 앞/뒤 글자 크기의 유의미한 차이가 없었다. 대상자의 글 자 크기 및 측정 예시는 Figure 2에 제시하였다.

Table 4. Descriptive statistics of letter size in sentence writing task (pixel)

\begin{tabular}{lccc}
\hline & $\mathrm{PD}(\mathrm{N}=38)$ & $\mathrm{NA}(\mathrm{N}=25)$ & $t$ \\
\hline Whole syllable & $3107.19231(1524.14749)$ & $4085.42462(1930.40684)$ & $-2.240^{*}$ \\
First 3-syllable & $3585.28070(1751.36122)$ & $4619.92000(1943.89652)$ & $-2.196^{*}$ \\
Final 3-syllable & $3125.53509(1658.90861)$ & $4207.24000(2450.05583)$ & $-2.092^{*}$
\end{tabular}

Values are presented as mean (SD).

$\mathrm{PD}=$ patients with Parkinson's disease; NA= normal adults. ${ }^{*} p<.05$.
PD1

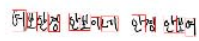

PD2

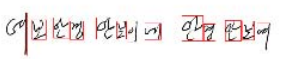

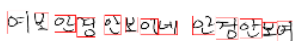

PD3
NA2

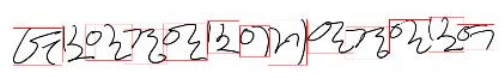

Figure 2. Letter size examples of PD and NA subject.

$\mathrm{PD}=$ patients with Parkinson's disease; $\mathrm{NA}=$ normal adults. 
Table 5. Descriptive statistics of writing speed in sentence writing task $(\mathrm{mm} / \mathrm{ms})$

\begin{tabular}{lccc}
\hline & $\mathrm{PD}(\mathrm{N}=38)$ & $\mathrm{NA}(\mathrm{N}=25)$ & $t$ \\
\hline Whole syllable & $.04117(.01503)$ & $.06114(.02006)$ & $-4.512^{* * *}$ \\
First 3-syllable & $.04200(.01477)$ & $.06058(.02007)$ & $-4.232^{* * *}$ \\
Final 3-syllable & $.04198(.01704)$ & $.06356(.02301)$ & $-4.273^{* * *}$
\end{tabular}

Values are presented as mean (SD).

$\mathrm{PD}=$ patients with Parkinson's disease; NA = normal adults.

${ }^{* * *} p<.001$.

\section{쓰기 속도 차이}

문장 쓰기 과제를 실시하여 집단 간 쓰기 속도의 차이를 살펴본 결과(Table 5), 전체 음절에서 $\mathrm{PD}$ 집단 평균 $.04117(\mathrm{SD}=.01503)$ 로, $\mathrm{NA}$ 집단 평균 $.06114(\mathrm{SD}=.02006)$ 보다 유의미하게 쓰기 속도가 느린 것으로 나타났다 $\left(t_{(61)}=-4.512, p=.000\right)$. 앞 3 음절에서 $\mathrm{PD}$ 집 단은 평균 $.04200(\mathrm{SD}=.01477)$ 으로, $\mathrm{NA}$ 집단 평균 $.06058(\mathrm{SD}=$ $.02007)$ 보다 유의미하게 느린 것으로 나타났다 $\left(t_{(61)}=-4.232, p=.000\right)$. 뒤 3음절에서 $\mathrm{PD}$ 집단은 평균 $.04198(\mathrm{SD}=.01704)$ 로, $\mathrm{NA}$ 집단 평균 $.06356(\mathrm{SD}=.02301)$ 보다 유의미하게 느린 것으로 나타났다 $\left(t_{(61)}=\right.$ $-4.273, p=.000)$.

각 집단의 앞 3 음절과 뒤 3 음절 쓰기 속도의 차이를 살펴본 결과, $\mathrm{PD}$ 집단은 $t_{(37)}=.017 p=.987, \mathrm{NA}$ 집단은 $t_{(24)}=-1.580 p=.127$ 로 두 집단 모두 앞/뒤쓰기 속도의 유의미한 차이가 없었다.

\section{필압, 글자 크기, 쓰기 속도 간의 상관}

필압, 글자 크기, 쓰기 속도 간의 상관이 있는지 살펴보기 위해 각 집단에서 상관분석을 실시한 결과(Table 6), $\mathrm{PD}$ 집단은 필압과 쓰 기 속도 간의 상관계수 .354 , 글자 크기와 쓰기 속도 간의 상관계수 .744로 정적 상관이 있는 것으로 나타났으며, 필압과 글자 크기 간 의 유의미한 상관은 나타나지 않았다.NA 집단은 글자 크기와쓰기 속도 간의 상관계수.806으로 정적 상관이 있는 것으로 나타났으며, 필압과 글자 크기, 필압과 쓰기 속도 간의 유의미한 상관은 없었다.

\section{논의 및 결론}

본 연구는 PD 집단과 NA 집단의 필압, 글자 크기, 쓰기 속도를 살펴보고, 세 변인 간의 관련성을 설명함으로써 $\mathrm{PD}$ 의 쓰기 특성을 확인하고자 하였다.

첫 번째로, 쓰기를 위한 기초적인 운동 양상을 확인하기 위하여 글자 쓰기가 아닌 가로/세로 점선 따라 그리기 과제에서의 수행력 을 측정하였을 때, 필압에서는 두 집단 간의 차이가 나타나지 않았 으나, 쓰기 속도는 $\mathrm{PD}$ 집단이 NA 집단보다 느린 것이 관찰되었다.
Table 6. The correlation coefficient among pen pressure, letter size, and writing speed in PD and NA group

\begin{tabular}{llcc}
\hline & & Pen pressure & Letter size \\
\hline PD & Letter size & .250 & \\
& Writing speed & $.354^{*}$ & $.744^{* * *}$ \\
NA & Letter size & -.090 & \\
& Writing speed & -.197 & $.806^{* * *}$ \\
\hline
\end{tabular}

${ }^{*} p<.05,{ }^{* * *} p<.001$.

$\mathrm{PD}=$ patients with Parkinson's disease; $\mathrm{NA}=$ normal adults.

이러한 결과는 $\mathrm{PD}$ 의 대표적인 임상 특징인 서동증의 증상이 단순 한 움직임을 반영하는 과제를 수행할 때의 운동 속도에서 드러난 것으로 해석할 수 있다. 서동증은 근육의 강직으로 인해 움직임이 줄어들고, 움직임이 느려지는 증상으로(Espay et al., 2009; Smits et al., 2014), PD 환자의 10 명 중 8 명 정도에서 관찰되는 흔한 증상이 다. 서동증은 운동의 계획, 시작, 집행 모든 단계에서 나타날 수 있 으며(Jankovic, 2008), 이로 인해 운동의 시작이 지연되고, 운동이 시작된 후에도 속도가 현저히 저하된다(Taleb et al., 2017; Yu, van Gemmert, \& Chang, 2016; Zham et al., 2017). 또한, 본 연구에 참여 한 $\mathrm{PD}$ 환자들은 과제 수행 시에 점선을 똑바로 따라 그리는 것이 어렵다고 빈번히 호소하였고 일부 $\mathrm{PD}$ 환자의 경우 과제 수행 전 본 인의 운동기능 저하를 호소하기도 하였다(예: 떨림 때문에 직선으 로 따라 그리지 못할 것 같다). 문장 쓰기와는 달리 점선 따라 그리 기 과제는 종료 지점이 명확하게 명시되어 있으므로 본인의 결함을 보상하기 위하여 종료 지점에서 주저하거나 신중을 기하는 심리적 양상으로 반영되면서 과제 수행 속도에 영향을 주었을 수도 있겠다.

더불어 흥미로운 점은 이후 이루어진 문장 쓰기 과제에서 측정 된 쓰기 속도를 확인해보았을 때, $\mathrm{PD}$ 집단뿐만 아니라 NA 집단 또 한 가로/세로 점선 따라 그리기 과제의 속도가 문장 쓰기 과제의 속 도보다 느린 것이 관찰되었다(PD 집단: 가로/세로 .02665 < 문장 쓰기 .04117, NA 집단: 가로/세로.04874 < 문장 쓰기 .06114). 점선 따라 그리기 과제의 경우 기초적인 운동능력을 확인하는 보다 단 순한 과제로 고안하였으나, 실제의 수행에서는 대상자들이 노력을 하면서 과제를 수행하는 양상이 관찰되었다. 이렇게 예상과 실제 결과가 다른 이유는 다음과 같이 생각해볼 수 있다. 시각적으로 제 시된 점선을 보고 손을 사용하여 따라 그리게 되므로 시각-운동 통합(visual-motor integration) 기능이 요구된다. 시각-운동 통합 기능은 시각적인 정보를 처리하면서 동시에 결부되는 운동을 협응 시키기 위하여 인지적 요소를 처리하는 고차원적인 인지 과정이다 (Frostig, 1972; Solomon \& O’brien, 2011; Weil \& Amundson, 1994). 따라서 철자체계가 이미 확립되어 있는 능숙한 쓰기 능력을 보유 
한 성인이라면 비교적 쉬운 자소와 음소가 일대일로 대응하는 항 목으로 이루어진 문장 받아쓰기보다, 화면에 제시된 점선을 똑같 이 따라 그리는 과제에서 시각-운동의 통합 처리 과정을 통해 더욱 주의를 기울이는 인지적 처리과정이 가중되면서(Hargrave, Jones, \& Davidson, 2016) 더 많은 시간을 필요로 하기 때문에(Drotár et al., 2016) 따라 그리는 속도에 영향을 주었을 가능성이 있는 것으로 해석할 수 있겠다.

두 번째로, 본 연구의 주요 목적인 문장 쓰기 과제에서의 필압, 크 기, 속도를 살펴보았을 때, 모든 측면에서 PD 집단은 NA 집단에 비 하여 저하된 수행력을 보였다. 먼저, 필압은 PD 집단이 NA 집단 보 다 전체 음절, 앞 3 음절, 뒤 3 음절에서 모두 필압이 약한 것으로 나 타났다. 기저핵 병변에 의하여 근육이 수축되어 이완되지 않는 강 직 증상은 $\mathrm{PD}$ 의 주요 임상 특성으로, 이들은 운동 시 근긴장을 조 절하는 데 어려움을 겪으며(Duffy, 2013), 운동의 범위가 제한되고, 근력이 상당히 약화되는 증상(Corcos, Chen, Quinn, McAuley, \& Rothwell, 1996; Ondo \& Satija, 2007)을 보인다. 이러한 증상은 연 속적으로 이루어지는 보행 시 족압이 저하되고 추진력이 떨어지면 서 보행 속도가 느려지는 결과로 나타나기도 하고(Lee et al., 2007), 말 산출 시 음성의 강도(loudness)가 저하되는 발성부전(hypophonia)으로 반영되기도 하며(Kim, 2012), 악력 측정 시 집는 힘과 쥐 는 힘이 모두 떨어지면서 일상생활에서의 동작 수행에 어려움을 겪 는 결과로 관찰되기도 한다(Lee, Kim, Kim, \& Kim, 2006). 본 연구 의 결과는 손을 매개체로 사용하여 팔과 손목 및 손가락의 움직임 이 요구되는 쓰기 활동에서도 글자를 쓸 때 펜을 누르는 힘이 저하 된 것으로 나타남으로써, 강직으로 인한 힘의 약화가 쓰기 수행 시 필압으로도 반영된 것으로 해석할 수 있다. 또한, 문장 쓰기 과제 전 에 이루어진 가로/세로 점선 따라 그리기 과제에서는 두 집단 간의 필압 차이가 나타나지 않았으나 문장 쓰기 과제에서는 $\mathrm{PD}$ 집단이 $\mathrm{NA}$ 집단에 비하여 필압이 저하된 것으로 나타났다. 이러한 결과는 점선과 같이 일방향으로 이루어지는 손의 움직임보다 글자 쓰기에 서는 음절의 구성에 필요한 자소의 크기 조절과 획 간의 연결을 하 는 다각적인 일련의 움직임에서(Yoon et al., 2006) 힘을 유지하고 조절하는 것이 더욱 어려움을 겪는 것(Rosenblum, Samuel, Zlotnik, Erikh, \& Schlesinger, 2013)으로 볼 수 있다. 따라서 파킨슨병 환자의 필압 특성을 살펴보기 위해서는 단순한 움직임을 살펴보는 과제가 아닌 문장 쓰기와 같은 과제가 더 도움을 줄 수 있음을 보여 준다. 문장의 앞과 뒤 부분의 필압을 비교하였을 때, 두 집단 모두 앞 3음절보다 뒤 3 음절에서 필압이 강해지는 양상을 보였는데, 이 는 도구의 영향으로 설명할 수 있다. 먼저, 태블릿 PC의 액정에 쓰 기 수행 시 발생할 수 있는 손날의 습기나 땀 등으로 인해 손이 옆으
로 이동하는 것이 어려워질 수 있고, 그로 인해 손의 위치와 글자를 써 나가는 펜의 위치가 상대적으로 가까워지면서 문장의 뒷부분으 로 갈수록 액정을 누르는 압력이 부과되었을 가능성이 있다. 또한, 마찰력은 일반적으로 접촉면에 작용하며, 외력과는 항상 반대 방 향으로 작용하기 때문에, 마찰계수가 낮은 매끄러운 표면에서 가 하는 외력은 증가하고, 마찰계수가 높은 표면에 가하는 외력은 감 소한다. 본 연구에서 사용된 태블릿 PC의 유리 액정과 같이 마찰계 수가 낮은 표면에 글자를 쓸 경우 태블릿 PC의 유리 액정과 디지털 펜의 플라스틱 펜촉으로 인한 마찰 감소를 보상하기 위하여 필압 이 점차 증가하며, 반대로 종이와 연필을 사용하는 것처럼 마찰계 수가 높은 표면에 글자를 쓸 경우에는 필압이 점차감소한다고 보고 한 선행연구(Alamargot \& Morin, 2015; Wann \& Nimmo-Smith, 1991)의 결과를 지지한다.

글자 크기 또한 $\mathrm{PD}$ 집단이 $\mathrm{NA}$ 집단 보다 전체 음절, 앞 3 음절, 뒤 3음절에서 모두 글자 크기가 작은 것으로 나타났다. 그러나 앞/뒤 의 수행력을 비교해보면 PD 집단에서는 앞 3 음절보다 뒤 3 음절에 서 글자 크기가 작아지는 양상이 나타났으나, NA 집단은 앞 3 음절 과 뒤 3음절의 글자 크기가 유사한 것으로 나타났다. 이러한 결과 는 그간 이루어진 $\mathrm{PD}$ 의 소자증과 관련한 선행연구(Chang et al., 2016; Kim et al., 2015)의 결과와 동일한 연구 결과이다. 본 연구에 서는 PD가 보일 수 있는 점진적 소자증 및 일관적 소자증 모두가 관찰되었다. 먼저 점진적 소자증과 같이 글자 크기가 작아지는 소 견의 원인은 다음과 같이 설명할 수 있다. $\mathrm{PD}$ 는 근육의 강직으로 인해 운동의 범위도 작아지는데, 이는 보행 시 보폭이 좁아지는 것 이나, 말운동 측면에서 반복적으로 일어나는 교대운동속도(alternative motion rate, AMR) 과제 수행 시 입술 운동의 범위가 감소되 며 말뭉침이 관찰되는 것과 같이 쓰기 수행 시에도 손의 움직임이 작아짐에 따라 글자 크기가 점진적으로 작아진 것으로 해석할 수 있다. 일관적 소자증의 경우에는 운동 수행 시 움직임의 크기를 측 정하고, 상황에 따른 행동을 준비하고 촉진하는 내적움직임(endokinetic)의 동기체계로서의 역할을 담당하는 기저핵 병변에 기인한 것으로 해석할 수 있다. 기저핵은 보행 시 보폭을 측정 및 조절하거 나 말운동 시 조음기관의 움직임을 조절하는 것으로 알려져 있으 므로 쓰기 수행 시에도 글자의 높이와 너비 등의 크기를 측정하고, 다양한 음절에 따라 적절히 반응하여 조절하는 역할을 담당하게 된다. 그러므로 $\mathrm{PD}$ 는 이러한 역할을 담당하는 기저핵의 손상으로 인해 전반적인 글자 크기가 작아지는 것으로 해석된다. 한편으로는 $\mathrm{PD}$ 는 외적움직임(exokinetic)을 담당하는 소뇌는 비교적 건재하기 때문에, 가령 시각적 참조물을 제시하는 등 외부적 단서(external cue)의 도움을 제공할 경우 운동 수행력이 향상될 수 있다(Kim et 
al., 2015; Nieuwboer et al., 2009b; Wu \& Hallet, 2008). Kim 등(2015) 은 시공간적으로 각 자소들이 사각형의 형태 안에서 모아쓰는 형 식(Yoon et al., 2006)의 한글의 특수성을 반영하여 PD 환자에게 각 음절별 정사각형의 가이드라인을 제시한 결과, 모든 음절의 크 기가 증가하였다고 보고하였다. 그러나 본 연구의 문장 쓰기 수행 에서 유일한 외부적 단서는 PD 환자 본인이 이미 쓴 글자들이며, 그 문장 자극 또한 다양한 음절들로 구성되어 있고 음소배열의 방향 이 일관적이지 않으므로 일종의 가이드라인처럼 활용할 수가 없었 던 것으로 생각된다. 결국 앞 글자를 다음 글자의 단서로 활용할 수 없기 때문에 전반적으로도 글자의 크기를 크게 쓰지 못한 것으로 해석할 수 있다.

쓰기 속도에서도 PD 집단은 NA 집단 보다 전체 음절, 앞 3음절, 뒤 3음절에서 모두 쓰기 속도가 느린 것으로 나타났다. 이러한 결 과는 앞서 논의하였듯이 서동증으로 인하여 쓰기 수행 시 정상인 과 비교하여 PD 환자의 쓰기 속도가 느리게 나타난 것으로 해석되 며, 선행연구(Eckert, Peschel, Heinze, \& Rotte, 2006; Lange et al., 2006; Rosenblum et al., 2013; Smits et al., 2014; Taleb et al, 2017)의 결과를 지지한다. 특히 두 집단은 모두 앞 3 음절과 뒤 3음절의 쓰기 속도가 유사한 것으로 나타났으므로 앞서 언급한 글자 크기 결과 와 연관 지어 볼 때, $\mathrm{PD}$ 환자는 글자 크기가 점점 작아졌지만 획의 길이를 감안하여 측정한 쓰기 속도는 앞 3음절과 뒤 3음절의 차이 없이 지속적으로 느린 것이 흥미롭다. 그 동안 $\mathrm{PD}$ 는 서동증이 주요 특징임에도 불구하고 말운동이나 보행운동 측면에서 관찰되는 가 속화되는 조음 운동 속도 및 종종 걸음 등이 임상적으로 보고되어 서로 상충되는 개념인 서동과 가속성이 동시에 나타나는 것으로 오 인되기도 한다. 그러나 실제로는 운동 범위가 제한되면서 부수적으 로 가속성이 나타나게 되는 것이므로(Denny et al., 1976) 운동범위 나 크기를 통제하는 경우에는 실제의 운동 속도가 느릴 수 있다. 즉, 말운동 측면에서도 조음 운동 범위의 제한에 따른 부정확한 조음 이나 말뭉침 등으로 인하여 실제의 속도가 빠르지 않더라도 빠르다 고 느낄 수 있으며(Kent \& Rosenbek, 1982; Weismer, 1984), 실제 말속도가 정상인과 비교하여 빠르지 않음에도 불구하고 $\mathrm{PD}$ 의 말 속도가 빠르게 느껴진다는 연구 결과(Torp \& Hammen, 2000)가 이를 지지한다. 따라서 글자 크기가 작아짐에 따라 쓰기에 소요되 는 시간(duration)은 짧아지는 것으로 보일 수 있으나 본 연구에서 는 글자 크기를 통제하는 측면에서 각 자소를 이루는 획의 길이를 자소를 쓴 소요시간으로 나누어 속력을 확인하는 과정을 통하여 글자를 쓰는 속도는 빨라지지 않고 여전히 느린 것을 확인하였다.

마지막으로 PD 집단에서는 필압과 쓰기 속도, 글자 크기와 쓰기 속도 간의 정적 상관이 나타났으며, NA 집단에서는 글자 크기와 쓰
기 속도 간의 정적 상관이 나타났다. 두 집단은 공통적으로 글자 크 기와 쓰기 속도 간의 높은 정적 상관을 보였는데, 이는 글자 크기의 영향을 받을 수 있는 쓰기 속도를 자소의 길이를 소요시간으로 나 눈 속력으로 분석한 것에 따른 결과로 해석된다. NA 집단과 달리 $\mathrm{PD}$ 집단에서는 필압과 쓰기 속도 간의 정적 상관이 나타났는데, 이 는 PD 환자가 쓰기 수행 시 글자를 쓸 때 펜을 누르는 힘의 저하와 글자를 쓰는 속도의 저하와의 관련성을 나타낸다. 이러한 결과는 $\mathrm{PD}$ 환자의 필압과 $\mathrm{PD}$ 환자에서 보이는 서동증과 같은 운동 증상 이 가장 높은 관련을 보였다고 보고한 선행연구(Taleb et al., 2017) 와 일치하는 결과로, 근육의 강직으로 인한 힘의 저하(필압)와 운 동 범위의 제한에 따라 속도(쓰기 속도)도 함께 저하됨을 시사한 다. 반면, 두 집단 모두 필압과 글자 크기 간의 상관은 나타나지 않 았는데, 이는 크기에 따라 글자를 쓰는 힘을 조절하는 것이 아님을 나타낸다. 예를 들어, 글자를 크게 써도 흘려 쓰는 경우 필압이 약 하게 나타날 수 있으며, 글자를 작게 써도 펜을 눌러쓰는 경우 필압 이 강하게 나타날 수 있는 등 개인의 글자를 쓰는 방식에 따라 다양 한 양상으로 나타날 수 있기 때문에 관련성이 높지 않은 것으로 해 석된다. 또한, NA 집단은 필압과 쓰기 속도 간의 상관이 나타나지 않았는데, 이는 손목과 손가락의 협응이 유연하게 이루어지는 NA 의 경우, 글자를 쓰는 힘을 조절하는 것과 상관없이 쓰기 속도 및 글 자 크기가 일정하게 유지됨에 따라 관련성이 높지 않은 것으로 해 석된다.

본 연구는 한글을 사용하는 $\mathrm{PD}$ 환자를 대상으로 글자 크기뿐만 아니라 필압과 쓰기 속도를 함께 측정하였으며, 태블릿 PC와 소프 트웨어를 활용하여 대상자의 쓰기 수행력을 객관적으로 수치화함 으로써, $\mathrm{PD}$ 환자의 쓰기에서 관찰될 수 있는 다양한 운동학적 관 점을 확인하였다는 것에 의의가 있다. 본 연구의 제한점 및 후속 연 구를 위한 제언은 다음과 같다. 첫째, $\mathrm{PD}$ 는 주 증상 부위(dominant side)에 따라 운동 증상이 다르게 나타나는 것으로 알려져 왔고, 특 히 쓰기 활동은 손잡이와 주 증상 부위가 수행력에 영향을 미칠 수 있다. 따라서 본 연구의 PD 환자들을 신경과 전문의가 실시한 UPDRS-partIII를 검토하여 대상자의 주 증상 부위를 왼쪽 20 명, 오른 쪽 18 명으로 나눈 후 두 집단의 연령, 교육년수, MoCA-K 점수, K$\mathrm{BDI}$ 점수, 발병 후 경과 기간, UPDRS-part III 점수, H\&Y 척도를 통해 배경정보를 확인하고, 문장 쓰기 과제에서의 평균 필압, 평균 쓰기 속도, 평균 글자 크기를 살펴보았다. 주 증상 부위에 따른 두 집단의 배경정보 및 쓰기 수행력 모두 통계적으로 유의미한차이가 나지 않았다. 물론 본 연구에 포함된 대상자들은 발병 후 경과 기간 이 평균 $5.105(\mathrm{SD}=3.351)$ 년의 초기 환자들로, UPDRS-part III 점 수는 평균 $13.618(\mathrm{SD}=6.276)$ 로 신체 증상이 비교적 경미하였고, 
평균 $\mathrm{H} \& \mathrm{Y}$ 척도는 $1.592(\mathrm{SD}=0.518)$ 로 확인되었기 때문에 이러한 결과가 나타났을 가능성이 있다. 따라서 추후 연구에서는 주 증상 부위와 중증도에 따라 쓰기 수행력의 차이가 나타나는 지 확인할 필요가 있다. 둘째, 본 연구에서는 실제 연필 모양과 유사한 디지털 펜을 사용하여 최대한 자연스러운 쓰기 환경을 조성하고자 하였 다. 그러나 태블릿 PC는 유리 액정으로 이루어져 있으므로 대상자 에 따라서는 글자를 쓸 때 종이에 쓰는 것과는 다른 필기감으로 느 낄 수 있다. 따라서 후속 연구에서는 실제와 유사한 쓰기 환경 조성 을 위해 태블릿 PC 액정에 종이 질감의 필름을 부착하거나, 국외 연구들(Smits et al., 2014; Zham et al., 2017)과 같이 실제 종이를 올 려두고도 측정 가능한 기기를 사용한다면 실제 환경에서의 쓰기 특성을 반영해줄 수 있을 것으로 기대된다. 셋째, Playford 등(1992) 은 운동 시 $\mathrm{PET}$ 영상에서 정상 집단과 비교했을 때 $\mathrm{PD}$ 환자들의 보충운동영역과 배외측 전전두피질(dorsolateral prefrontal cortex) 에서 국소적인 대사저하를 보였으며, 이는 $\mathrm{PD}$ 의 운동 장애와 대뇌 피질의 대사저하와 관련이 있다고 시사하였다. 이에 후속 연구에서 쓰기 과제 수행과 더불어 PD 환자의 운동 영역 및 쓰기와 관련한 영역에서의 대사를 PET 영상을 통해 분석할 수 있다면 PD의 운동 학적인 쓰기 기제를 증명할 수 있을 것이다.

\section{REFERENCES}

Ahn, E. Y. \& Chung, H. A. (2009). A review on pathophysiology of Parkinson's disease. Journal of Occupational Therapy for the Aged and Dementia, 3(1), 1-9.

Alamargot, D., \& Morin, M. F. (2015). Does handwriting on a tablet screen affect students' graphomotor execution? A comparison between grades two and nine. Human movement science, 44, 32-41.

Becker, G., Müller, A., Braune, S., Büttner, T., Benecke, R., Greulich, W., ... \& Thümler, R. (2002). Early diagnosis of Parkinson's disease. Journal of neurology, 249(3), 40-48.

Chang, Y. W., Cho, S. R., Yoon, J. H., \& Kim, H. H. (2016). Micrographia in Parkinson's disease: comparison between horizontal and vertical handwritings. Communications Sciences \& Disorders, 21(4), 683-694.

Christensen, K. J., Multhaup, K. S., Nordstrom, S., \& Voss, K. (1991). A cognitive battery for dementia: development and measurement characteristics. Psychological Assessment: A Journal of Consulting and Clinical Psychology, 3(2), 168.

Corcos, D. M., Chen, C. M., Quinn, N. P., McAuley, J., \& Rothwell, J. C. (1996). Strength in Parkinson's disease: relationship to rate of force generation and clinical status. Annals of neurology, 39(1), 79-88.

Corti, O., Hampe, C., Darios, F., Ibanez, P., Ruberg, M., \& Brice, A. (2005).

Parkinson's disease: from causes to mechanisms. Comptes rendus biologies, 328(2), 131-142.

Denny-Brown, D. (1976). The role of the basal ganglia in the initiation of movement. In M. D. Yahr (Ed.), The basal ganglia (pp. 115-149). New York: Raven Pr.

Drotár, P., Mekyska, J., Rektorová, I., Masarová, L., Smékal, Z., \& FaundezZanuy, M. (2016). Evaluation of handwriting kinematics and pressure for differential diagnosis of Parkinson's disease. Artificial intelligence in Medicine, $67,39-46$.

Duffy, J. R. (2013). Motor Speech disorders: Substrates, differential diagnosis, and management (3rd ed.). St. Louis, MO: Elsevier Mosby.

Eckert, T., Peschel, T., Heinze, H. J., \& Rotte, M. (2006). Increased pre-SMA activation in early PD patients during simple self-initiated hand movements. Journal of neurology, 253(2), 199-207.

Espay, A. J., Beaton, D. E., Morgante, F., Gunraj, C. A., Lang, A. E., \& Chen, R. (2009). Impairments of speed and amplitude of movement in Parkinson's disease: a pilot study. Movement Disorders, 24(7), 1001-1008.

Fearnley, J. M., \& Lees, A. J. (1991). Ageing and Parkinson's disease: substantia nigra regional selectivity. Brain, 114(5), 2283-2301.

Freed. D. B. (2012). Motor speech disorders: diagnosis and treatment (2nd ed.). Clifton Park, NY: Delmar Cengage Learning.

Frostig, M. (1972). Visual perception, integrative functions and academic learning. Journal of Learning Disabilities, 5(1), 5-19.

Gelb, D. J., Oliver, E., \& Gilman, S. (1999). Diagnostic criteria for Parkinson disease. Archives of neurology, 56(1), 33-39.

Hargrave, S. L., Jones, S., \& Davidson, T. L. (2016). The outward spiral: a vicious cycle model of obesity and cognitive dysfunction. Current opinion in behavioral sciences, 9, 40-46

Health Insurance Review \& Assessment Service. (2018). http://www.hira.or.kr/ Jankovic, J. (2008). Parkinson's disease: clinical features and diagnosis. Journal of neurology, neurosurgery \& psychiatry, 79(4), 368-376.

Kent, R. D., \& Rosenbek, J. C. (1982). Prosodic disturbance and neurologic lesion. Brain and language, 15(2), 259-291.

Kim, E. J., Lee, B. H., Park, K. C., Lee, W. Y., \& Na, D. (2005). Micrographia on free writing versus copying tasks in idiopathic Parkinson's disease. Parkinsonism \& related disorders, 11(1), 57-63.

Kim, H. (2012). Neurologic Speech-Language Disorders. Seoul: SigmaPress. Kim, H., Yoon, J. H., \& Nam, H. S. (2015). Efficacy of language-appropriate 
cueing on micrographia in K orean patients with Parkinson's disease. Geriatrics \& gerontology international, 15(5), 647-651.

Lange, K. W., Mecklinger, L., Walitza, S., Becker, G., Gerlach, M., Naumann, M., \& Tucha, O. (2006). Brain dopamine and kinematics of graphomotor functions. Human movement science, 25(4-5), 492-509.

Lee, C. N., Eom, G. M., Park, K. W., Koh, S. B., Kim, B. J., Oh, K. M., ... \& Lee, D. H. (2007). Dynamic foot pressure measurement in Parkinson's disease with foot scan system. Journal of Korean Neural Association, 25(2), 172179.

Lee, J. Y., Lee, D. W., Cho, S. J., Na, D., Jeon, H. J., Kim, S. K., ... \& Cho, M. J. (2008). Brief screening for mild cognitive impairment in elderly outpatient clinic: validation of the Korean version of the Montreal Cognitive Assessment. Journal of geriatric psychiatry and neurology, 21(2), 104-110.

Lee, S. J., Kim, S. H., Kim, H. T., \& Kim, M. J. (2006). The comparison of hand grip and pinch strength between Parkinson's disease and control group. Korean Journal Clinical Geriatrics, 7(4), 433-439.

Lee, Y. H., \& Song, J. Y. (1991). A study of the reliability and the validity of the BDI, SDS, and MMPI-D scales. Korean Journal of Clinical Psychology, 10(1), 98-113.

Letanneux, A., Danna, J., Velay, J. L., Viallet, F., \& Pinto, S. (2014). From micrographia to Parkinson's disease dysgraphia. Movement Disorders, 29(12), 1467-1475.

McLennan, J. E., Nakano, K., Tyler, H. R., \& Schwab, R. S. (1972). Micrographia in Parkinson's disease. Journal of the neurological sciences, 15(2), 141-152.

Morrish, P. K., Rakshi, J. S., Bailey, D. L., Sawle, G. V., \& Brooks, D. J. (1998). Measuring the rate of progression and estimating the preclinical period of Parkinson's disease with [18F] dopa PET. Journal of Neurology, Neurosurgery \& Psychiatry, 64(3), 314-319.

National Institutes of Health. (2004). Image J. https://www.nih.gov/

Na, D. \& Yoon, J. H. (inpress). Brief Agraphia Test.

Nieuwboer, A., Baker, K., Willems, A. M., Jones, D., Spildooren, J., Lim, I., \& Rochester, L. (2009b). The short-term effects of different cueing modalities on turn speed in people with Parkinson's disease. Neurorehabilitation and neural repair, 23(8), 831-836.

Ondo, W. G., \& Satija, P. (2007). Withdrawal of visual feedback improves micrographia in Parkinson's disease. Movement disorders: official journal of the Movement Disorder Society, 22(14), 2130-2131.

Playford, E. D., Jenkins, I. H., Passingham, R. E., Nutt, J., Frackowiak, R. S. J., \& Brooks, D. J. (1992). Impaired mesial frontal and putamen activation in Parkinson's disease: a positron emission tomography study. Annals of Neu- rology: Official Journal of the American Neurological Association and the Child Neurology Society, 32(2), 151-161.

Rosenblum, S., Samuel, M., Zlotnik, S., Erikh, I., \& Schlesinger, I. (2013). Handwriting as an objective tool for Parkinson's disease diagnosis. Journal of neurology, 260(9), 2357-2361.

Seol, W. G. (2008). Genes causing familial Parkinson's disease. Korean Journal of Psychopharmacology, 19(1), 29-37.

Shukla, A. W., Ounpraseuth, S., Okun, M. S., Gray, V., Schwankhaus, J., \& Metzer, W. S. (2012). Micrographia and related deficits in Parkinson's disease: a cross-sectional study. BMJ open, 2(3), e000628.

Smits, E. J., Tolonen, A. J., Cluitmans, L., van Gils, M., Conway, B. A., Zietsma, R. C., \& Maurits, N. M. (2014). Standardized handwriting to assess bradykinesia, micrographia and tremor in Parkinson's disease. PloS one, 9(5), e97614.

Solomon. W., \& O’brien. J. C. (2011). Pediatric skills for occupational therapy assistants (3rd ed.). St. Louis, MO: Mosby.

Taleb, C., Khachab, M., Mokbel, C., \& Likforman-Sulem, L. (2017). Feature selection for an improved Parkinson's disease identification based on handwriting. In 2017 IEEE 1st International Workshop on Arabic Script Analysis and Recognition (ASAR), 52-56.

Taleb, C., Khachab, M., Mokbel, C., \& Likforman-Sulem, L. (2018). A Reliable method to predict Parkinson's disease stage and progression based on handwriting and re-sampling approaches. In 2018 IEEE 2nd International Workshop on Arabic and Derived Script Analysis and Recognition (ASAR), 7-12.

Torp, J. N., \& Hammen, V. L. (2000). Perception of Parkinsonian speech rate. Journal of Medical Speech-Language Pathology, 8(4), 323-329.

Wann, J., \& Nimmo-Smith, I. (1991). The control of pen pressure in handwriting: a subtle point. Human Movement Science, 10(2-3), 223-246.

Weil, M. J., \& Amundson, S. J. C. (1994). Relationship between visuomotor and handwriting skills of children in kindergarten. American Journal of Occupational Therapy, 48(11), 982-988.

Weismer, G. (1984). Articulatory characteristics of Parkinsonian dysarthria: Segmental and phrase-level timing, spirantization, and glottal-supraglottal coordination. In M.R. McNeil, J.C. Rosenbek \& A.E. Aronson (Eds.), The dysarthrias: physiology, acoustics, perception, management (pp. 101-130). San Diego: College-Hill Press.

Wu, T., \& Hallett, M. (2008). Neural correlates of dual task performance in patients with Parkinson's disease. Journal of Neurology, Neurosurgery \& Psychiatry, 79(7), 760-766. 
Yoon, J. H., Shin, J. C., Kim, D. Y., Suh, M. K., \& Kim, H. (2006). Korean agraphia subsequent to right hemispheric lesion. Speech Sciences, 13(3), 121132.

Yoon, J. H., Na, D., \& Kim, H. (2009). Agraphia in Dementia. Dementia and Neurocognitive Disorders, 8(1), 1-14.

Yu, N. Y., Van Gemmert, A. W., \& Chang, S. H. (2016). Characterization of graphomotor functions in individuals with Parkinson's disease and essential tremor. Behavior research methods, 49(3), 913-922.
Zham, P., Kumar, D. K., Dabnichki, P., Poosapadi Arjunan, S., \& Raghav, S. (2017). Distinguishing different stages of Parkinson's disease using composite index of speed and pen-pressure of sketching a spiral. Frontiers in neurology, 8, 435.

Zham, P., Raghav, S., Kempster, P., Arjunan, S. P., Wong, K., Nagao, K. J., \& Kumar, D. K. (2019). A kinematic study of progressive micrographia in Parkinson's disease. Frontiers in neurology, 10, 1-8. 


\section{국문초록}

파킨슨병의 쓰기 특성: 필압, 크기, 속도를 중심으로

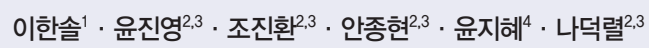

'한림대학교 보건과학대학원 언어병리학과, ${ }^{2}$ 성균관대학교 의과대학 삼성서울병원 신경과, ${ }^{3 ㅅ ㅏ ㅁ ㅅ ㅓ ㅇ ㅅ ㅓ ㅇ ㅜ ㄹ ㅂ ㅕ ㅇ ㅇ ㅝ ㄴ ~ ㄴ ㅚ ㅅ ㅣ ㄴ ㄱ ㅕ ㅇ ㅅ ㅔ ㄴ ㅌ ㅓ, ~}{ }^{4}$ 한림대학교 언어청각학부

배경 및 목적: 파킨슨병(PD)의 운동 장애는 쓰기 수행에서 글자 크기뿐만 아니라 필압과 속도 측면에도 영향을 미칠 수 있다. 본 연구 의 목적은 $\mathrm{PD}$ 의 쓰기 특성을 필압, 크기, 속도를 중심으로 살펴보고자 하였다. 방법: $\mathrm{PD} 38$ 명과 정상 성인(NA) 25 명, 총 63 명을 대상으 로, 태블릿 PC와 디지털펜을 가지고 필압, 획의 길이, 쓰기 시간을 측정할 수 있는 소프트웨어를 사용하여 점선 따라 그리기와 문장 쓰 기 과제를 실시하고, 필압, 글자 크기, 쓰기 속도를 분석하였다. 결과: 점선 따라 그리기 과제에서 필압은 두 집단 간 차이가 없었고, 쓰기 속도는 PD 집단이 NA 집단 보다 느렸다. 문장 쓰기 과제에서 PD 집단이 NA 집단 보다 필압이 저하되고, 글자 크기가 작으며, 쓰기 속도 가 느렸다. 두 집단은 공통적으로 글자 크기와 쓰기 속도 간의 정적 상관이 나타났으며, $\mathrm{PD}$ 집단은 필압과 쓰기 속도 간의 정적 상관도 나타났다. 논의 및 결론: 본 연구 결과는 $\mathrm{PD}$ 로 인하여 강도, 크기, 속도 등의 운동 능력을 조절하는 것의 어려움이 쓰기 수행 시 필압, 글 자 크기, 쓰기 속도로 반영될 수 있음을 보여준다. 본 연구는 그간 글자 크기에만 초점이 맞추어졌던 $\mathrm{PD}$ 의 쓰기 특성에서 필압이나 쓰 기 속도와같이 다양한 요소를 측정하는 것이 중요함을 확인하였다는 점에서 의의가 있다.

핵심어: 파킨슨병, 쓰기, 필압, 쓰기 속도

이 논문은 2017년 정부(산업통상자원부)의 재원으로 한국산업기술평가관리원의 지원을 받아 수행된 연구임(과제번호 10063384).

이 논문은 2019년도 한림대학교 교비연구비에 의하여 연구되었음(No. HRF-201912-007).

\section{참고문헌}

김향희(2012). 신경언어장애. 서울: 시그마프레스.

나덕렬, 윤지혜 (출판중). Brief Agraphia Test.

설원기(2008). 가족성 PD의 원인 유전자. 대한정신약물학회지, 19(1),29-37.

안은영, 정현애(2009). $\mathrm{PD}$ 의 병태생리. 고령자·치매작업치료학회지, 3(1), 1-9.

이승조, 김승현, 김희태, 김미정(2006). 파킨슨병 환자의 손의 악력에 대한 정상인과의 비교 분석. 대한임상노인의학회지, 7(4), 433-439.

이영호, 송종용(1991). BDI, SDS, MMPI-D 척도의 신뢰도 및 타당도에 대한 연구. 대한진단의학회지, 10(1), 98-113.

이찬녕, 엄광문, 박건우, 고성범, 김병조, 오경미, 김호정, 이대희(2007). Foot Scan System을 이용한 파킨슨병 환자의 역동적 족압 분석. 대한신경과학 회지, 25(2), 172-179.

윤지혜, 나덕렬, 김향희(2009). 치매와 실서증. 대한치매학회지, 8(1), 1-14.

윤지혜, 신지철, 김덕용, 서미경, 김향희(2006). 우반구 손상 환자의 한글 실서증 특징. 음성과학, 13(3), 121-132.

장윤원, 조성래, 윤지혜, 김향희(2016). 파킨슨병의 소자증 특성: 가로쓰기와세로쓰기의 비교. Communications Sciences \& Disorders, 21(4), 683-694.

\section{ORCID}

이한솔(제1저자, 대학원생 http://orcid.org/0000-0002-6290-2566); 윤진영(공동저자, 교수 http://orcid.org/0000-0003-3350-5032) 조진환(공동저자, 교수 http://orcid.org/0000-0002-9145-6729); 안종현(공동저자, 임상강사 http://orcid.org/0000-0002-6415-2316) 윤지혜(교신저자, 교수 http://orcid.org/0000-0003-1403-2276); 나덕렬(공동저자, 교수 http://orcid.org/0000-0003-1572-7862) 